\title{
Biologics in Leprosy: A Systematic Review and Case Report
}

\author{
Anna L. Cogen, ${ }^{1 *}$ Eglantine Lebas, ${ }^{2}$ Barbara De Barros, ${ }^{3}$ James P. Harnisch, ${ }^{1}$ William R. Faber, ${ }^{4}$ Diana N. Lockwood, ${ }^{3}$ and \\ Stephen L. Walker ${ }^{3}$ \\ ${ }^{1}$ Division of Dermatology, Department of Medicine, University of Washington, Seattle, Washington; ${ }^{2}$ Department of Dermatopathology, St John's \\ Institute of Dermatology, Guy's and St Thomas' NHS Foundation Trust, London, United Kingdom; ${ }^{3}$ London School of Hygiene and Tropical \\ Medicine, London, United Kingdom; ${ }^{4}$ Department of Dermatology, Amsterdam UMC, University of Amsterdam, Amsterdam, The Netherlands
}

\begin{abstract}
Tumor necrosis factor (TNF)- $\alpha$ inhibitors increase susceptibility to tuberculosis, but the effect of biologics on susceptibility to leprosy has not been described. Moreover, biologics may play a role in treating erythema nodosum leprosum (ENL). The objectives of this systematic review were to determine whether the development of clinical leprosy is increased in patients being treated with biologics and to assess the use of biologics in treating leprosy reactions. A systematic literature review was completed of patients with leprosy who received treatment with biologics either before or after a diagnosis of leprosy was confirmed. All studies and case reports were included for qualitative evaluation. The search yielded 10 cases (including one duplicate publication) of leprosy diagnosed after initiation of TNF- $\alpha$ inhibitors and four case reports of refractory ENL successfully treated with infliximab or etanercept. An unpublished case of persistent ENL responsive to infliximab is also presented. These data demonstrate that the use of TNF- $\alpha$ inhibitors may be a risk factor for developing leprosy or reactivating subclinical infections. Leprosy can present with skin lesions and arthritis, so leprosy should be considered in patients presenting with these signs before starting treatment with these agents. Leprosy should be considered in patients who develop worsening eruptions and neurologic symptoms during treatment with TNF$\alpha$ inhibitors. Finally, TNF- $\alpha$ inhibitors appear effective in some cases of refractory ENL.
\end{abstract}

\section{INTRODUCTION}

Leprosy, also known as Hansen's disease, is caused by the obligate intracellular acid-fast bacilli Mycobacterium leprae or Mycobacterium lepromatosis and acquired primarily through inhalation. Tropism for Schwann cells, keratinocytes, and macrophages leads to infection of the skin and nerves with resultant nerve damage from inflammation. ${ }^{1,2}$ The Ridley-Jopling classification describes a clinicopathologic spectrum, in which tuberculoid leprosy (TT) and lepromatous leprosy (LL) are at opposite poles. Tuberculoid leprosy is characterized by a robust cellmediated immune response and elimination of $M$. leprae, with patients having few well-defined skin lesions and localized peripheral nerve damage. By contrast, patients with borderline lepromatous (BL) and LL mount insufficient cell-mediated immune responses and ineffective humoral responses, allowing for replication and dissemination of intracellular $M$. leprae. ${ }^{3}$ Leprosy is complicated by immune-mediated inflammatory reactions, namely, Type 1 reactions (reversal reactions) and erythema nodosum leprosum (ENL, Type 2 reactions). Erythema nodosum leprosum is characterized by fever, crops of tender erythematous cutaneous nodules, neuritis, arthritis, orchitis, lymphadenitis, and iritis. This painful multisystem disorder complicates $50 \%$ of LL and approximately $5-10 \%$ of $\mathrm{BL}$ patients. ${ }^{4}$ Multidrug therapy (MDT), comprising rifampicin, dapsone, and clofazimine, is the cornerstone of treatment for leprosy. ${ }^{1}$

Patients on TNF- $\alpha$ inhibitors are at increased risk of primary tuberculosis (TB) and reactivation, but the risk of leprosy is unknown. ${ }^{5}$ We performed a systematic review to determine whether biological medication (biologic) use was associated with development of leprosy and whether biologics have been used in the treatment of leprosy. In this qualitative systematic review, we discuss cases of leprosy identified after biologic use and successful treatment of ENL with TNF- $\alpha$ inhibitors.

*Address correspondence to Anna L. Cogen, Division of Dermatology, Department of Medicine, University of Washington, 4225 Roosevelt Way NE, Seattle, WA 98105. E-mail: alcogen@uw.edu

\section{METHODS}

Overview. A systematic literature review was performed to identify cases of leprosy diagnosed after initiation of a biologic and leprosy reactions treated with a biologic. One author (A. L. C.) reviewed publications titles, abstracts, and full-text articles to assess for eligibility. The preferred reporting items for systematic review and meta-analysis protocols 2015 guideline was used to prepare this systematic review. Case reports are included in tables in which qualitative findings are summarized.

Inclusion and exclusion criteria. All articles describing patients who developed leprosy after beginning a biologic or patients with leprosy treated with a biologic were included. We excluded reports of cases that did not include patients with leprosy or in which biologics were not used. We also excluded review articles, commentaries, and articles lacking patient details. Although the term "biologic" can include vaccines and recombinant human proteins, such as insulin and recombinant human interferon, among others, we included only reports of humanized monoclonal antibodies and receptors.

Literature search. We searched PubMed, LILACS, and Cochrane Library articles on July 4, 2018 (Supplemental Table 1). Our search included all languages. A manual check of the references of the included full-text articles was performed. The search of PubMed, LILACS, and Cochrane Library revealed 525 records. There was one duplicate, leaving 524 records to be screened. The records were screened by title and abstract. Five hundred six studies were excluded because the publications did not concern leprosy or biologics, were basic science studies, or were review articles. Eighteen full-text articles were assessed for eligibility, with three records excluded for insufficient patient details (diagnosis, treatment, or course were not addressed) or because it was a commentary. ${ }^{6-8}$ A flowchart of included studies is depicted in Figure 1.

Fifteen full-length articles were assessed and included in the systematic review. A hand-search of these articles did not reveal additional relevant cases. Of the 15 included articles, 11 case reports detailed the diagnosis of leprosy after initiation of a TNF- $\alpha$ inhibitor and four case reports described patients 


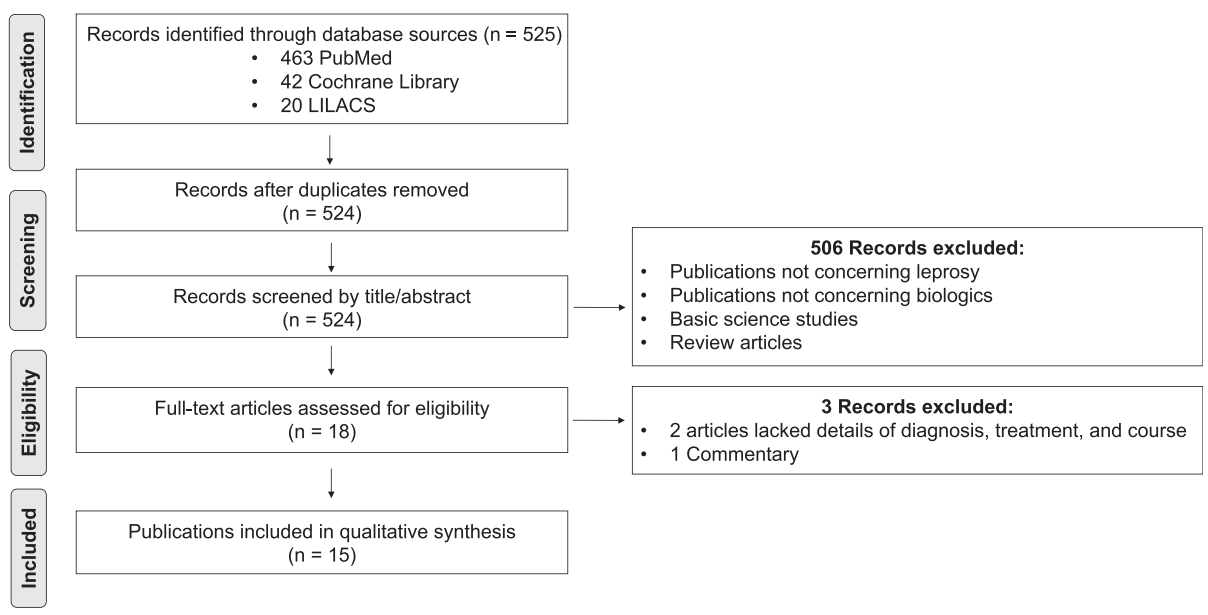

FIGURE 1. Flowchart of included studies.

who received a biologic for treatment of ENL. Authors of the four case reports were contacted for follow-up information. We received data from the case reports published by Faber et al. ${ }^{9}$ and Ramien et al. ${ }^{10}$ and included the information in this review.

In addition, a coauthor (J. P. H.) provided an unpublished case of a patient with refractory ENL treated with biological medication, which was included. A qualitative evaluation was conducted on all cases included in this systematic review.

\section{RESULTS}

Diagnosis and development of leprosy after initiation of a biologic. In total, 11 publications describe patients diagnosed with leprosy after the initiation of infliximab, adalimumab, and/or etanercept (Table 1). Of note, one author confirmed that a duplicate case report was published, which is reflected in Table $1 .{ }^{11,12}$ In addition, a communication discussed a patient who developed leprosy after infliximab administration, but it is unclear whether this patient is the subject of a latter case report. ${ }^{13}$ Two large database analyses of biologic side-effect analyses were also found. In Wallis et al., data on granulomatous infections in the setting of TNF- $\alpha$ antagonists were collected through the adverse event reporting system of the U.S. Food and Drug Administration from January 1998 to September $2002 .{ }^{8}$ In this study, one patient on infliximab developed leprosy. Because additional patient information was not provided, the publication was excluded from this review. Similarly, Titton et al. ${ }^{7}$ published a study on the Brazilian biologic registry, which reported one case of $T$, but because of lack of details, this case was also omitted from this review. Overall, 10 patients were included with ages ranging from 37 to 76 years and leprosy acquisition in Brazil, United States, Greece, and Spain.

Inflammatory arthritis was the indication for biologics in nine of the 10 patients, and at least nine of the 10 patients received prior immunosuppressive or immunomodulating medications, including methotrexate, hydroxychloroquine, corticosteroids, and/or leflunomide. ${ }^{11,12,14-19}$ (Table 1). In four of the 10 patients, cutaneous findings, including psoriasiform plaques, ${ }^{17}$ exfoliative erythroderma, ${ }^{20}$ nodules (clinically diagnosed as rheumatoid nodules), ${ }^{18}$ and an abdominal rash, were noted before initiation of biologics. ${ }^{14}$ The diagnosis of leprosy was confirmed by skin biopsies of new cutaneous eruptions.
Treatment of ENL with biologics. We identified four published case reports of ENL refractory to standard therapies treated with TNF- $\alpha$ inhibitors (Table 2).

Faber et al. ${ }^{9}$ described a 52-year-old woman from Paraguay, who developed BL while living in Argentina. She was treated with WHO multibacillary MDT (rifampicin, dapsone, and clofazimine) and developed painful erythematous nodules and plaques consistent with ENL. She was treated with prednisolone, thalidomide, and pentoxifylline, but discontinuation led to frequent recurrence of ENL. After anti-ENL medications were stopped and MDT completed, the patient was started on infliximab (5 mg/kg), noting improvement within hours. She received additional infliximab infusions on weeks 2 and 6 and did not develop a recurrence of ENL after the third infusion.

Ramien et al. ${ }^{10}$ reported a 33-year-old woman, from the Philippines, with ENL complicating LL. The ENL was severe and refractory to multiple courses of prednisone and thalidomide. ${ }^{10} \mathrm{~A}$ trial of clofazimine, prednisone, and thalidomide resulted in adverse effects. Treatment with etanercept $50 \mathrm{mg}$ weekly for 2 years allowed for a slow prednisone taper, discontinuation of thalidomide, and subsequent resolution of ENL. She experienced one recurrence, which responded to a 3-month course of thalidomide. The authors communicated that she remained asymptomatic for 2.5 years after etanercept was stopped.

Santos et al. ${ }^{21}$ reported a case of a 40-year-old man who developed recurrent ENL complicating LL and was treated with thalidomide and prednisone for approximately 1 year. Etanercept resulted in improvement within 48 hours. The patient experienced one flare requiring prednisone. After 11 months, there were no signs of reaction while receiving etanercept $50 \mathrm{mg}$ weekly and prednisone $10 \mathrm{mg}$ daily.

The fourth published case report by Chowdhry et al. ${ }^{22}$ describes a 49-year-old man with ENL complicating LL despite treatment with prednisolone, clofazimine, thalidomide, clarithromycin, ofloxacin, and azathioprine. He also developed adverse effects from thalidomide and prednisolone. ${ }^{22}$ The ENL persisted for 6 months with development of necrotic cutaneous lesions, neuritis, epididymo-orchitis, and lymphadenitis. Etanercept at $50 \mathrm{mg}$ weekly led to mild improvement within 48 hours and significant improvement after 12 weeks of therapy; during this time, prednisolone was discontinued after a "slow taper" of unspecified duration. 
BIOLOGICS IN LEPROSY: A SYSTEMATIC REVIEW AND CASE REPORT

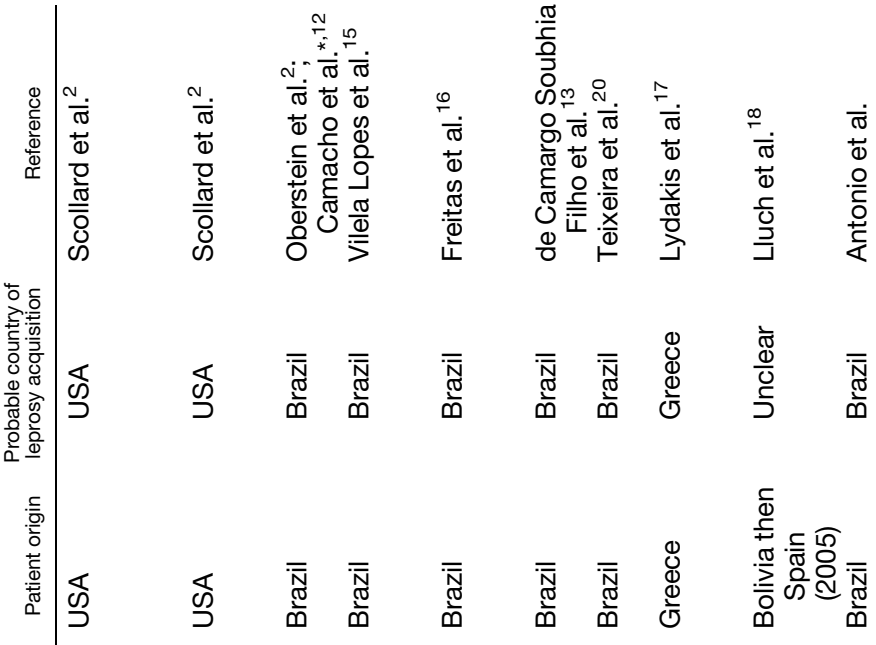

흥들

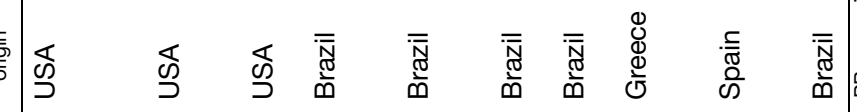

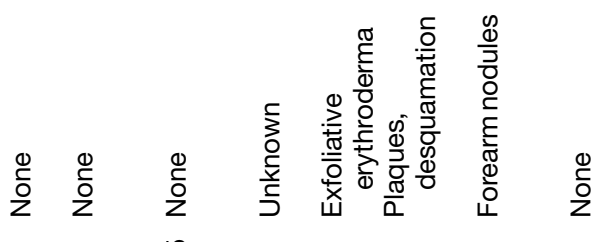

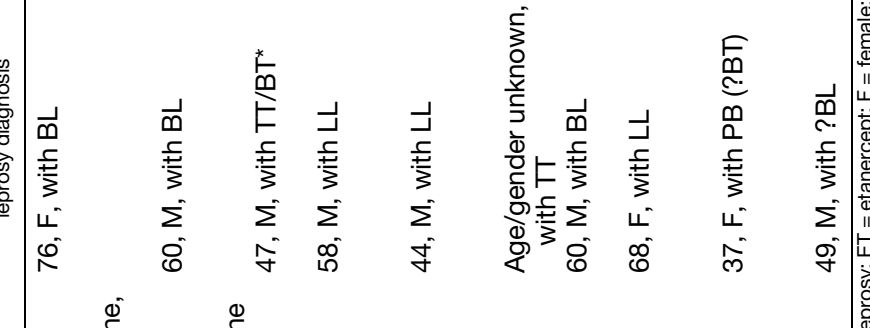

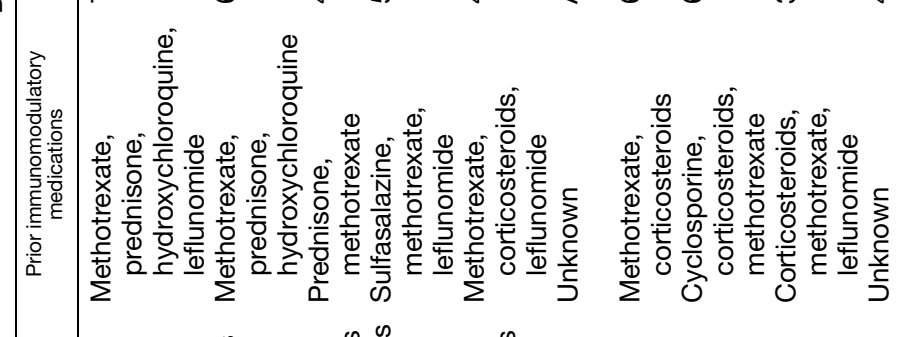

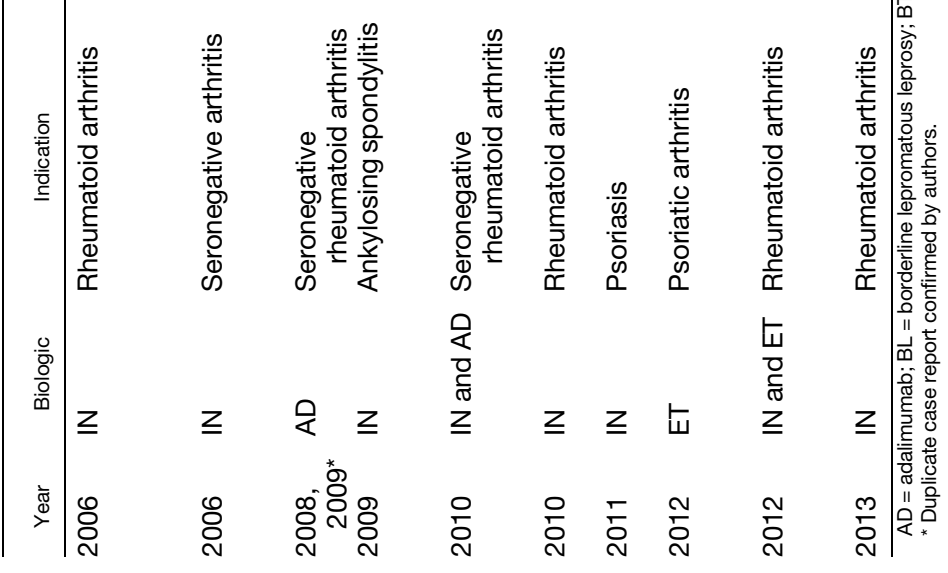


TABLE 2

Reports of ENL treated with TNF- $\alpha$ inhibitors

\begin{tabular}{|c|c|c|c|c|c|c|c|c|}
\hline Year & Biologic & Indication & $\begin{array}{l}\text { Age } \\
\text { (years) } \\
\text { gender }\end{array}$ & Treatment and outcome & Report origin & Patient origin & $\begin{array}{l}\text { Probable country of } \\
\text { leprosy acquisition }\end{array}$ & Reference \\
\hline 2006 & $\begin{array}{c}\text { Infliximab } 5 \\
\mathrm{mg} / \mathrm{kg}\end{array}$ & $\begin{array}{l}\text { Persistent ENL despite } \\
\text { prednisolone, } \\
\text { thalidomide, and } \\
\text { pentoxifylline. }\end{array}$ & $52, F$ & $\begin{array}{l}\text { Rapid improvement } \\
\text { within hours. Received } \\
\text { three infusions of } \\
\text { infliximab. Symptom- } \\
\text { free for } 12 \text { months. }\end{array}$ & Netherlands & Paraguay & Argentina* $^{*}$ & Faber et al. ${ }^{9}$ \\
\hline 2011 & $\begin{array}{c}\text { Etanercept } 50 \\
\text { mg/week }\end{array}$ & $\begin{array}{l}\text { Persistent ENL and } \\
\text { experienced adverse } \\
\text { effects of } \\
\text { corticosteroids, } \\
\text { clofazimine, and } \\
\text { thalidomide. }\end{array}$ & $33, F$ & $\begin{array}{l}\text { Received etanercept, } \\
\text { prednisone, and } \\
\text { thalidomide. Steroids } \\
\text { stopped after } 6 \text { weeks } \\
\text { and thalidomide after } 6 \\
\text { months. Symptom-free } \\
\text { for } 6 \text { months on } \\
\text { etanercept alone. }\end{array}$ & Canada & Philippines & Philippines & Ramien et al. ${ }^{10}$ \\
\hline 2016 & $\begin{array}{c}\text { Etanercept } 50 \\
\text { mg/week }\end{array}$ & $\begin{array}{l}\text { Persistent ENL despite } \\
\text { prednisolone, } \\
\text { thalidomide, } \\
\text { pentoxifylline, and } \\
\text { azathioprine. } \\
\text { Experienced adverse } \\
\text { effects of thalidomide } \\
\text { and prednisolone. }\end{array}$ & $49, \mathrm{M}$ & $\begin{array}{l}\text { Etanercept and taper of } \\
\text { prednisolone led to } \\
\text { improvement of ENL at } \\
\text { week 12. Prednisolone } \\
\text { discontinued (unclear } \\
\text { date). Etanercept } \\
\text { tapered to biweekly. }\end{array}$ & India & India† & India & Chowdhry et al. ${ }^{22}$ \\
\hline 2017 & $\begin{array}{c}\text { Etanercept } 50 \\
\text { mg/week }\end{array}$ & $\begin{array}{l}\text { Persistent ENL despite } \\
\text { prednisone and } \\
\text { thalidomide. }\end{array}$ & $40, \mathrm{M}$ & $\begin{array}{l}\text { Etanercept and } \\
\text { prednisone } 10 \mathrm{mg} \\
\text { weekly led to control of } \\
\text { ENL. }\end{array}$ & Brazil & Brazil & Brazil & Santos et al. ${ }^{21}$ \\
\hline 2019 & $\begin{array}{c}\text { Infliximab } 5 \\
\mathrm{mg} / \mathrm{kg}\end{array}$ & $\begin{array}{l}\text { Persistent ENL despite } \\
\text { thalidomide, } \\
\text { prednisone, } \\
\text { clofazimine, and } \\
\text { cyclophosphamide. }\end{array}$ & $29, \mathrm{M}$ & $\begin{array}{l}\text { Infliximab (7 infusions) } \\
\text { and slow taper of } \\
\text { prednisone led to } \\
\text { control of ENL. Now, } \\
\text { off infliximab. }\end{array}$ & USA & Samoa & Samoa & $\begin{array}{l}\text { Unpublished } \\
\text { new case } \\
\text { report. }\end{array}$ \\
\hline
\end{tabular}

${ }^{*}$ Born in Paraguay, but developed leprosy while living in Argentina.

$\dagger$ Patients likely from India as no additional information about the place of birth or travel is given.

\section{CASE REPORT}

A 28-year-old man from Samoa was initially treated for $L L$ in Samoa with WHO multibacillary MDT for 6 months before migrating to Seattle, WA. While on MDT in Samoa, the patient was placed on prednisone (30-40 mg daily) for ENL for the duration of the MDT treatment. He presented to our clinic with polyarthritis, peripheral neuritis, painful cutaneous nodules, and uveitis. Treatment was changed to clofazimine $100 \mathrm{mg}$ daily, levofloxacin $500 \mathrm{mg}$ daily, and clarithromycin $500 \mathrm{mg}$ daily for the leprosy, and thalidomide $200 \mathrm{mg}$ daily, prednisone $40 \mathrm{mg}$ daily, and prednisolone eye drops for the ENL. Rifampicin was not used because of interactions with prednisone. Dapsone resistance was confirmed by polymerase chain reaction. Given his minimal response, clofazimine was increased to $150 \mathrm{mg}$ daily, thalidomide was increased to $300 \mathrm{mg}$ daily, and prednisone was increased to $80 \mathrm{mg}$ daily, but the ENL remained poorly controlled. Trimethoprim/sulfamethoxazole (TMP-SMX) added for prophylaxis of Pneumocystis jiroveci. He was hospitalized three times for possible sepsis, but infectious studies were negative and slit-skin smears for $M$. leprae at six sites demonstrated a $5+$ bacterial index (BI). While hospitalized, he received prednisone $100 \mathrm{mg}$ twice daily. Thalidomide was discontinued, and cyclophosphamide $100 \mathrm{mg}$ daily was initiated and increased to $100 \mathrm{mg}$ twice daily with prednisone continued at $120 \mathrm{mg}$ daily. Two months later, the cutaneous nodules ulcerated, acral edema intensified, and his peripheral neuritis and polyarthritis remained symptomatic. Cyclophosphamide was discontinued, and minocycline $100 \mathrm{mg}$ daily was added. Improvement was minimal, so he was started on infliximab 5 $\mathrm{mg} / \mathrm{kg}$. During the infusion, his symptoms dramatically improved, and the prednisone was slowly tapered to $30 \mathrm{mg}$ daily. Because of ENL flares, infliximab infusions were given 2 and 7 weeks later. His ENL continued to flare, so he received a fourth infusion at week 16 while on prednisone $60 \mathrm{mg}$ daily. He had two further infusions at weeks 78 and 88 because of ulcerative cutaneous ENL nodules and painful peripheral neuritis and simultaneously required prednisone $80 \mathrm{mg}$ daily. His antimicrobial regimen (clofazimine $150 \mathrm{mg}$, minocycline $100 \mathrm{mg}$, clarithromycin $500 \mathrm{mg}$, levofloxacin $500 \mathrm{~g}$, and TMPSMX) was unchanged. At week 99, his ENL deteriorated, requiring a seventh and final infusion of infliximab $5 \mathrm{mg} / \mathrm{kg}$. During this infusion, he experienced hypotension, edema, and throat tightening, which responded to $50 \mathrm{mg}$ intravenous hydrocortisone and diphenhydramine. All seven infliximab infusions were used for intense flares of ENL, and each infusion was $5 \mathrm{mg} / \mathrm{kg}$. His weight was roughly $171 \mathrm{~kg}$ for all infusions. Immediate and dramatic improvement occurred with each infusion, but slowly symptoms returned, and eventually intense flares occurred. Prednisone was continued between infusions at variable dosage the entire time. Prednisone was slowly reduced and discontinued along with the antimicrobials 4 years after the onset of ENL. At the time of discontinuation, his BI was $2+$ at one of six slit-skin smear sites, but bacteria were beaded and fragmented. He was followed for three more years and did not develop a recurrence of his ENL. 


\section{DISCUSSION}

For the cases that reported leprosy after initiation of a TNF- $\alpha$ inhibitor, the indications for the use of a TNF- $\alpha$ inhibitor included inflammatory arthritis (presumed seronegative arthritis, rheumatoid arthritis, psoriatic arthritis, and ankylosing spondylitis) and psoriasis. Cutaneous signs (rashes and nodules) were present in at least four of 10 patients before receiving a TNF- $\alpha$ inhibitor. The well-established connection between the inhibition of TNF- $\alpha$ and TB reactivation may similarly hold true for leprosy, as suggested by the described case reports. The rapidity with which patients developed signs of leprosy after receiving the biologic does suggest a possible recrudescence of latent leprosy or initial misdiagnosis. In Brazil, Indonesia, and Nepal, there is ongoing endemic transmission of leprosy, unlike Greece and Spain, which have very low rates of endemic transmission. The lack of reported cases from India is unexpected because India reports the highest number of leprosy cases globally, with 126,164 in 2017. India's health system also allows for the use of advanced treatment modalities, including biologics. ${ }^{23}$ Furthermore, lack of availability and financial constraints may account for the decreased use of biologics in endemic countries.

Leprosy patients frequently present with cutaneous manifestations such as nodules, patches, plaques, neuritis, and peripheral neuropathy. Moreover, signs and symptoms of inflammatory arthritis, such as dactylitis, tenosynovitis, and arthritis, may be present in leprosy patients, leading to diagnostic challenges. In a study profiling rheumatologic manifestations in leprosy patients, Singh et al. ${ }^{24}$ found that 23 of 100 patients with leprosy exhibited small joint arthritis and some patients experienced tenosynovitis, enthesitis, and dactylitis. Prasad et al. ${ }^{25}$ conducted a retrospective analysis of leprosy patients and found that 14 of 44 patients had small joint arthritis mimicking rheumatoid arthritis and seven cases mimicking spondyloarthropathy. Arthritis and tenosynovitis were found to be associated with leprosy reactions in 28 cases. ${ }^{25}$ It is possible that several patients in this systematic review may have had subclinical leprosy or were misdiagnosed. Furthermore, prior use of immunosuppression may have contributed to susceptibility to infection. In addition, the use of TNF- $\alpha$ inhibitors in leprosy patients before completion of MDT may lead to reduced efficacy of the antimicrobial agents or promotion of infection by $M$. leprae. Finally, in non-endemic regions, leprosy is less likely to be considered in patients with inflammatory arthritis. Thus, differentiating inflammatory arthritis from leprosy remains a challenge, and leprosy should be considered in such patients with cutaneous, neurologic, and musculoskeletal symptoms.

We identified four published cases and one unpublished report of refractory ENL treated effectively with a TNF- $\alpha$ inhibitor. Erythema nodosum leprosum's chronicity and frequent recurrence warrant many individuals to seek treatment at leprosy referral centers. ${ }^{4}$ Because ENL is associated with a pro-inflammatory immune response and elevated TNF- $\alpha$ levels, treatment includes the use of immunosuppressants. ${ }^{26}$ First-line treatments include prolonged courses of corticosteroids, thalidomide, and clofazimine, yet each carry numerous and often limiting adverse effects. Oral corticosteroids are associated with hypertension, hyperglycemia, Cushing's syndrome, osteopenia/osteoporosis, cataract formation, diabetes mellitus, and increased risk for infections. Thalidomide requires enrollment in the System for Thalidomide Education and Prescribing Safety program because of teratogenicity. ${ }^{27}$ Despite these adverse events, corticosteroids and thalidomide are often effective treatment modalities. Even when thalidomide is available, a significant proportion of individuals require additional anti-ENL therapy. The cases identified in this systematic review demonstrate the challenges associated with refractory ENL, medication adverse effects, and the benefit of treatment with TNF- $\alpha$ inhibitors.

Of the five cases of refractory ENL treated with TNF- $\alpha$ inhibitors, four tapered corticosteroids while receiving TNF- $\alpha$ inhibitors and three experienced sustained remission after discontinuation of the TNF- $\alpha$ inhibitor. Often, patients with chronic ENL require long-term maintenance corticosteroids. The enduring efficacy of TNF- $\alpha$ inhibitors may signify diseasemodifying activity, with earlier use possibly preventing prolonged exposure to other agents.

Limitations include publication bias from underreporting of cases, reports in which biologics were not effective, and a lack of prospective controls due to the nature of case reports. A trial would overcome the aforementioned limitations. The absence of outcome measures when evaluating ENL is another weakness of this study. A validated clinical severity scale of ENL has been published and is being used in a trial investigating the efficacy of methotrexate in the treatment of ENL. ${ }^{28}$ The use of this scale would be helpful in evaluating ENL in future studies. Limited access to long-term follow-up information is another limitation of this study, as remission and adverse effects remain primary challenges in treating ENL.

The small number of case studies in this review has demonstrated that TNF- $\alpha$ inhibitors are useful in treating some individuals with chronic, refractory ENL or those unable to tolerate other ENL therapies because of adverse effects. Further work is required to establish the role of TNF- $\alpha$ inhibitors in ENL and their potential to improve outcomes for patients in settings where these medications are affordable and appropriate monitoring available. Increasing availability of biologics for ENL patients in leprosy-endemic countries may reduce the burden of ENL on patients and leprosy referral centers, although overuse and exacerbation of other infections need to be considered. The indications for and access to anti-TNF therapy, including more affordable biosimilars, continue to increase. Finally, patients who have ever resided in leprosy-endemic regions with unexplained cutaneous signs or symptoms may benefit from evaluation by a dermatologist before starting TNF$\alpha$ inhibitors, given the diagnostic challenges and overlap between leprosy and rheumatologic conditions.

Received August 21, 2019. Accepted for publication December 30, 2019.

Published online March 9, 2020.

Note: Supplemental table appears at www.ajtmh.org.

Acknowledgment: We would like to thank Anne E. Burdick for helpful discussion.

Authors' addresses: Anna L. Cogen and James P. Harnisch, Division of Dermatology, Department of Medicine, University of Washington, Seattle,WA, E-mails: alcogen@uw.edu and jphdermid@hotmail.com. Eglantine Lebas, Department of Dermatopathology, St John's Institute of Dermatology, Guy's and St Thomas' NHS Foundation Trust, London, United Kingdom, E-mail: eglantinelebas@hotmail.com. Barbara De Barros, Diana N. Lockwood, and Stephen L. Walker, London School of Hygiene and Tropical Medicine, London, United Kingdom, 
E-mails: barbara.de-barros@lshtm.ac.uk, diana.lockwood@lshtm.ac. uk, and steve.walker@Ishtm.ac.uk. William R. Faber, Department of Dermatology, Amsterdam UMC, University of Amsterdam, Amsterdam, The Netherlands, E-mail: w.r.faber@amersterdamumc.nl.

\section{REFERENCES}

1. Britton WJ, Lockwood DN, 2004. Leprosy. Lancet 363: 12091219.

2. Scollard DM, 2008. The biology of nerve injury in leprosy. LeprRev 79: 242-253.

3. Ridley DS, Jopling WH, 1966. Classification of leprosy according to immunity. A five-group system. Int J Lepr Other Mycobact Dis 34: 255-273.

4. Walker SL et al.; Erythema Nodosum Leprosum International Study Group, 2015. ENLIST 1: an international multi-centre cross-sectional study of the clinical features of erythema nodosum leprosum. PLoS Negl Trop Dis 9: e0004065.

5. Baddley JW, Cantini F, Goletti D, Gomez-Reino JJ, Mylonakis E, San-Juan R, Fernandez-Ruiz M, Torre-Cisneros J, 2018. ESCMID study group for infections in compromised hosts (ESGICH) consensus document on the safety of targeted and biological therapies: an infectious diseases perspective (soluble immune effector molecules [1]: anti-tumor necrosis factoralpha agents). Clin Microbiol Infect 24 (Suppl 2): S10-S20.

6. Thangaraju P, Durai V, Showkath Ali MK, 2016. The role of etanercept in refractory erythema nodosum leprosum. Int $J$ Mycobacteriol 5: 368-369.

7. Titton DC et al., 2011. Brazilian biologic registry: BiobadaBrasil implementation process and preliminary results. Rev Bras Reumatol 51: 152-160.

8. Wallis RS, Broder MS, Wong JY, Hanson ME, Beenhouwer DO, 2004. Granulomatous infectious diseases associated with tumor necrosis factor antagonists. Clin Infect Dis 38: 1261-1265.

9. Faber WR, Jensema AJ, Goldschmidt WF, 2006. Treatment of recurrent erythema nodosum leprosum with infliximab. $N$ Engl J Med 355: 739.

10. Ramien ML, Wong A, Keystone JS, 2011. Severe refractory erythema nodosum leprosum successfully treated with the tumor necrosis factor inhibitor etanercept. Clin Infect Dis 52: e133-e135.

11. Oberstein EM, Kromo O, Tozman EC, 2008. Type I reaction of Hansen's disease with exposure to adalimumab: a case report. Arthritis Rheum 59: 1040-1043.

12. Camacho ID, Valencia I, Rivas MP, Burdick AE, 2009. Type 1 leprosy reaction manifesting after discontinuation of adalimumab therapy. Arch Dermatol 145: 349-351.

13. de Camargo Soubhia Filho G, Pires Rossi NC, Cordeiro Soubhia RM, Okino L, 2010. Micobacterioses relacionadas as terapias com imunobiologicos (anti-TNF-a). Rev Bras Med 70: 106-108.

14. Scollard DM, Joyce MP, Gillis TP, 2006. Development of leprosy and type 1 leprosy reactions after treatment with infliximab: a report of 2 cases. Clin Infect Dis 43: e19-e22.
15. Vilela Lopes R, Barros Ohashi C, Helena Cavaleiro L, de Britto Pereira Cruz R, da Veiga RR, Fernando Ribeiro Miranda M, Toshimitsu Yoshikawa G, 2009. Development of leprosy in a patient with ankylosing spondylitis during the infliximab treatment: reactivation of a latent infection? Clin Rheumatol 28: 615-617.

16. Freitas DS, Machado N, Andrigueti FV, Neto ETR, Pinheiro MM, 2010. Lepromatous leprosy associated with the use of anti-TNF alpha therapy: case report. Rev Bras Reumatol 50: 336-339.

17. Lydakis C, Ioannidou D, Koumpa I, Giannikaki E, Thalassinos E, Krasoudaki E, Miyakis S, 2012. Development of lepromatous leprosy following etanercept treatment for arthritis. Clin Rheumatol 31: 395-398.

18. Lluch P, Urruticoechea A, Lluch J, Moll MC, Matos M, Benet JM, Ene L, Canete JD, 2012. Development of leprosy in a patient with rheumatoid arthritis during treatment with etanercept: a case report. Semin Arthritis Rheum 42: 127-130.

19. Antonio JR, Soubhia RMC, Paschoal VD, Amarante CF, Travolo ARF, 2013. Biological agents: investigation into leprosy and other infectious diseases before indication. An Bras Dermatol 88 (6 Suppl 1): 23-25.

20. Teixeira FM, Vasconcelos LM, Rola Cde A, Prata de Almeida TL, Valenca JT Jr., Nagao-Dias AT, 2011. Secondary leprosy infection in a patient with psoriasis during treatment with infliximab. J Clin Rheumatol 17: 269-271.

21. Santos JRS, Vendramini DL, Nery JADC, Avelleira JCR, 2017. Etanercept in erythema nodosum leprosum. Bras Dermatol 92: 575-577.

22. Chowdhry S, Shukla A, D'Souza P, Dhali T, Jaiswal P, 2016. Treatment of severe refractory erythema nodosum leprosum with tumor necrosis factor inhibitor Etanercept. Int $\mathrm{J}$ Mycobacteriol 5: 223-225.

23. World Health Organization, 2018. Global leprosy update, 2017: reducing the disease burden due to leprosy. Wkly Epidemiol Rec 93: 444-456.

24. Singh R, Mahajan VK, Mehta KS, Thakur L, Chauhan PS, Gupta M, Rawat R, 2016. Profile of rheumatological manifestations in leprosy in a tertiary care hospital from Himachal Pradesh. Indian J Lepr 88: 13-19.

25. Prasad S et al., 2013. Leprosy revealed in a rheumatology clinic: a case series. Int J Rheum Dis 16: 129-133.

26. Polycarpou A, Walker SL, Lockwood DN, 2017. A systematic review of immunological studies of erythema nodosum leprosum. Front Immunol 8: 233

27. Zeldis JB, Williams BA, Thomas SD, Elsayed ME, 1999. S.T.E.P.S.: a comprehensive program for controlling and monitoring access to thalidomide. Clin Ther 21: 319-330.

28. Walker SL et al., 2017. A leprosy clinical severity scale for erythema nodosum leprosum: an international, multicentre validation study of the ENLIST ENL severity scale. PLoS NegI Trop Dis 11: e0005716. 